\title{
TROCA TRANSCENDENTAL, JUSTIÇA E DIREITOS HUMANOS EM OTFRIED HÖFFE*
}

\author{
TRANSCENDENTAL EXCHANGE, JUSTICE AND \\ HUMAN RIGHTS IN OTFRIED HÖFFE
}

Robinson dos Santos**

RESUMO - Um dos grandes problemas postos pelo tema dos direitos humanos à filosofia é, entre outros, o de sua fundamentação filosófica. No pano de fundo deste debate, surgem questões específicas: como se pode fundamentar/justificar filosoficamente a exigência de reconhecimento aos direitos humanos? Neste estudo, procuro abordar, de modo direto, o núcleo argumentativo sobre o qual está estruturada da proposta de Höffe. Para ele, os direitos humanos têm uma profunda relação com a noção de justiça. O conceito de justiça, na sua concepção, deve ser entendido fundamentalmente como troca (Gerechtigkeit als Tausch). Embora o conceito pareça demasiado simples, ele oferece uma série de dificuldades no que se refere à sua fundamentação.

PALAVRAS-CHAVE - Justiça, direitos humanos, interesses transcendentais, contratualismo, Otfried Höffe.

ABSTRACT - One of the major problems posed by the human rights issue to philosophy is its philosophical foundation. The background of this discussion raises questions such as: how can one philosophically explain / justify the demand for human rights recognition? This paper focuses on the argumentative basis on which Höffe structures his proposal. For him human rights are closely connected to the concept of justice. This concept must be understood primarily as an exchange (Gerechtigkeit als Tausch). Although the concept seems simple, it offers many difficulties regarding its foundation.

KEYWORDS - Justice, human rights, transcendental interests, contractualism, Otfried Höffe.

* Uma versão preliminar deste texto está publicada em: CARBONARI, P. C. (org.) Sentido Filosófico dos Direitos Humanos: Leituras do Pensamento Contemporâneo. (volume 2) Passo Fundo: IFIBE, 2009.

** Doutor em Filosofia pela Universidade de Kassel, Alemanha. Professor Adjunto no Departamento de Filosofia da Universidade Federal de Pelotas, RS, Brasil.

\begin{tabular}{|l|l|l|l|l|l|}
\hline Veritas & Porto Alegre & v. 56 & n. 1 & jan./abr. 2011 & p. 111-126 \\
\hline
\end{tabular}




\section{Posição do problema}

“Es genügt nicht, die Welt zu verändern. Das tun wir ohnehin. Und weitgehend geschieht das sogar ohne unser Zutun. Wir haben auch die Veränderung auch zu interpretieren. Und zwar, um diese zu verändern. Damit sich die Welt nicht weiter ohne uns verändere. Und nicht schließlich in eine Welt ohne uns"

(GÜNTHER ANDERS) ${ }^{1}$

A Declaração Universal dos Direitos Humanos completou, em 2008, sessenta anos de existência. Ela é inquestionavelmente um dos documentos mais importantes do século $\mathrm{XX}^{2}$. Não há a menor dúvida de que o tema dos direitos humanos está entre os principais assuntos debatidos no âmbito da filosofia contemporânea, especialmente em áreas como a ética, a filosofia política, a filosofia do direito e a filosofia da educação. Trata-se de um tema de interesse universal e, portanto, transcende as fronteiras disciplinares e culturais, na medida em que repercute internacionalmente ${ }^{3}$. Apesar de os direitos humanos terem alcançado um significado e relevância mundiais, de modo especial na política e no direito internacional, o debate filosófico contemporâneo mostra claramente o quanto não se consegue chegar a uma compreensão unívoca sobre a questãotema ( cf. LOHMANN, 1998, p. 62).

Um dos grandes problemas postos pelo tema dos direitos humanos à filosofia é, entre outros, o de sua fundamentação filosófica ${ }^{4}$. Quaisquer

1 "Não é suficiente transformar o mundo. Isso nós fazemos de qualquer modo. E, além do mais, isso acontece até mesmo sem a nossa ação. Nós temos também que interpretar esta transformação. E, na verdade, para modificá-la, afim de que o mundo não continue a mudar sem nós e não se tranforme, afinal, em um mundo sem nós".

2 Conforme GOSEPATH e LOHMANN, 1998, p. 7. Para uma leitura contemporânea sobre a problemática da fundamentação filosófica dos direitos humanos, vale conferir a coletânea organizada pelos referidos autores.

3 Indicador desta realidade é o volume de estudos realizados, sobretudo, a partir dos anos 90 e que ganham força ainda maior na entrada do século XXI não só no Brasil ou na América Latina, mas na América do Norte e na Europa, de modo especial.

4 A aparente simplicidade da questão esconde, como sabemos, dificuldades sutis e complexas que não se deixam resolver, nem por meio da redução ou simplificação da discussão a um problema de opção teórica, nem tampouco através do apelo à "autoridade" deste ou daquele intérprete. Justamente pelo fato de não haver uma compreensão unívoca também sobre a Moral e a Ética, suas características e o seu respectivo papel com relação ao Direito é que as divergências sobre o que sejam os direitos humanos implicam uma abordagem ampla e, portanto, de caráter filosófico. 
que sejam as pretensões de uma abordagem filosófica há que se levar em consideração as dificuldades originadas no fato de que os direitos humanos são, antes de mais nada, direitos de Estados concretos e, ao mesmo tempo, objeto de convenções internacionais (GOSEPATH e LOHMANN, 1998, p. 10). "A pretensão universal dos direitos humanos confronta, de longe, cada tematização filosófica com a multiplicidade de problemas das diferenças culturais e exige o trabalho conjunto das respectivas áreas científicas de diferentes culturas" (Idem, ibidem, p. 10).

No pano de fundo deste debate, surgem questões, entre as quais: como se pode fundamentar/justificar filosoficamente a exigência de reconhecimento aos direitos humanos? Se os direitos humanos devem valer para todos os humanos, eles não podem ser tributários ou dependentes de nenhum contexto cultural, histórico ou sociopolítico e, ao mesmo tempo, serem aceitos e possuir validade em todos eles. De que modo poder-se-á demonstrar a sua validade universal e necessária, isto é, de que maneira é possível sustentar que eles implicam uma obrigação de cada ser humano para cada (outro) ser humano e que, assim, deverão ser aceitos por todos independentemente das contingências que os influenciam? ${ }^{5}$ Como se pode perceber, a problemática da fundamentação envolve, desde o ponto de partida, a questão da universalidade.

Otfried Höffe, filósofo e professor catedrático da Universidade de Tübingen, encontra-se entre os autores que se dedicam a esta problemática na atualidade ${ }^{6}$. Neste trabalho, que é uma primeira aproximação com a questão posta, procuro abordar, de modo direto, o núcleo argumentativo sobre o qual está estruturada a proposta de Höffe: para ele, os direitos humanos têm uma profunda relação com aquilo que denominamos de justiça. Conforme Höffe, o conceito de justiça deve ser entendido

5 Para uma abordagem desta problemática, com ênfase nos problemas advindos do contexto cultural, vale conferir a coletânea organizada por GÖLLER, 1999.

6 Em suas pesquisas, o autor aborda, com expressiva produtividade, desde temas situados no âmbito da filosofia prática, de modo especial, nas áreas de ética, filosofia política e filosofia do direito, a partir da tradição, através de pensadores clássicos como Aristóteles, Hobbes e Kant, até a interlocução com pensadores contemporâneos como Rawls, Kelsen, Nozick e Habermas. A lista de seus trabalhos, que não apresentarei, aqui, de modo completo, é ampla e já conta com um número razoável de traduções do alemão para outros idiomas. Eu gostaria de destacar, neste espaço, especialmente aqueles trabalhos que estão traduzidos para o português e acessíveis, portanto, para o público que não lê em alemão. Estes são os livros introdutórios a Aristóteles e Kant, bem como, Justiça Política: Fundamentação de uma filosofia crítica do direito e do Estado (Politische Gerechtigkeit: Grundlegung einer kritischen Philosophie von Recht und Staat, 1987), A Democracia no Mundo de Hoje, (Demokratie im Zeitalter der Globalisierung, 1999) e O que é Justiça? (Gerechtigkeit: eine philosophische Einführung, 2001). 
fundamentalmente como troca ${ }^{7}$ (Gerechtigkeit als Tausch). Embora o conceito pareça demasiado simples, ele oferece uma série de dificuldades no que se refere à sua fundamentação.

O conceito de troca, bastante empregado, sobretudo, na área da economia, pode ser interpretado a partir de diversas e diferentes perspectivas. Pois bem, aqui, surge, de imediato, a pergunta: o que ele quer afirmar com o conceito de justiça como troca? Qual a relação deste conceito com a fundamentação dos direitos humanos? Como procurarei demonstrar, para Höffe, não se trata de qualquer tipo de troca, mas de uma troca transcendental (transzendentaler Tausch). O que ele quer asseverar, especificamente, com isso e a relevância deste argumento para o debate sobre a fundamentação dos direitos humanos é o que pretendo abordar em seguida.

\section{A dimensão fundamentalmente antropológica da questão}

Humanidade é ou, pelo menos deveria ser, o que nos torna essencialmente iguais como espécie e, ao mesmo tempo, é a qualidade peculiar que nos diferencia dos demais seres. O nosso comportamento e o modo pelo qual estruturamos a nossa vida não estão dados de antemão pela natureza. Precisamos viver em sociedade, condição pela qual somos inevitavelmente levados a um processo complexo em que o entendimento e o reconhecimento mútuo são condições de possibilidade da própria sociedade e, por consequência, do Estado. Entretanto, entendimento e reconhecimento não excluem por si só os conflitos (cf. HÖFFE, 1981, p. 100). O conceito de direitos humanos aponta para princípios universais e, portanto, trata-se de algo que diz respeito à humanidade ou, como afirma o autor, trata-se de "princípios da humanidade", "pois somente aqueles direitos são dignos de ser chamados de direitos humanos, que valem para todo o ser humano: independente de gênero e cor da pele, da origem, da raça, da língua, da opção política ou religiosa e também da posição social e econômica"8.

7 Embora o conceito de Gerechtigkeit als Tausch possa também ser traduzido como justiça como comutação, como prefere Tito Lívio Cruz Romão, o tradutor de Demokratie im Zeitalter der Globalisierung, o conceito de justiça como troca é legítimo e amplamente aceito entre os tradutores e intérpretes. Neste sentido, minha tradução/interpretação concorda com a perspectiva de Ernildo Stein, em Justiça Política, de Peter Naumann, em O que é Justiça? e de Thomas Kesselring (vide referência).

8 Idem, ibid., p. 102. Embora concorde com o conteúdo da afirmação citada, eu gostaria de fazer, aqui, uma observação. No que se refere ao uso do termo "raça", o autor incorre em um equívoco para o qual é importante um esclarecimento. O renomado pesquisador francês Jacques Ruffié, médico, biólogo e estudioso da genética das populações, afirma, em seu livro De la Biologie à la Culture (1976, p. 323-324), que: "Dado o progresso 
Quando nos referimos ao conjunto da humanidade são suprassumidas as diferenças particulares, as contingências históricas e locais, isto é, de tempo e de espaço. Os direitos humanos têm que valer independentemente destas contingências, pois, do contrário, eles mesmos tornam-se relativos. Desse modo, eles estão além da história e da geografia. Embora possam ter uma significação histórica e uma aplicação em determinado espaço ou contexto, isto é, no "aqui e agora", eles permanecem acima das particularidades e das especificidades dos diversos contextos, valendo ao mesmo tempo igualmente para todos eles. Ora, isso evidencia a sua pretensão de validade universal e isto significa validade inter/ transcultural e "transepocal".

$\mathrm{Na}$ base do discurso sobre os direitos humanos, pode ser constatada uma noção antropológica fundante. Eles são pensados de um modo paradoxal, isto é, embora devam abstrair as diferenças, não podem ser pensados puramente desde uma imagem abstrata e devem, por outro lado, considerar o ser humano na sua concretude, sem absolutizar as peculiaridades e particularidades deste ser, ou seja, sem se tornarem concretos demais. Só se entenderá de modo adequado o que são estes direitos, quando estiver compreendido o que e porque são humanos.

Se tomarmos a noção aristotélica do ser humano como animal político ou social por natureza, teremos um olhar certamente diferente daquele de Hobbes, que vê, no ser humano, muito mais a inclinação ao conflito (homem lobo do próprio homem) como característica fundamental. Não faltam exemplos históricos para que seja confirmada a tese de Hobbes, a qual defende que o ser humano homem é uma ameaça para si mesmo. Por outro lado, também não é preciso muito esforço para reconhecer a tese de Aristóteles ao afirmar que a sociabilidade humana é uma marca essencial do gênero. Se, de um lado, é possível, por meio da sociabilidade, a conquista de um estado de justiça e equilíbrio para a sociedade, através da influência de uns sobre outros, não é menos verdadeiro que o gênero humano pode, a qualquer momento, autoaniquilar-se pretensamente em nome da liberdade. Ambas, pois, são possibilidades muito presentes no ser humano, uma vez que o seu comportamento não é completamente pré-determinado pelos instintos, nem tampouco única e exclusivamente o

da genética humana, hoje em dia nenhum biólogo admite a existência de raças na espécie humana; alguns utilizam este termo, mas a maioria o despoja de seu sentido zoológico. [...] O conceito de raça biológica já não pode ser aplicado à espécie humana. No ser humano, a raça é mais um mito social do que um fenômeno biológico" (Grifos do autor). Ora a persistência do conceito, na atualidade, deve-se, segundo Ruffié, ao conservadorismo típico das ciências, característica presente também na própria Biologia. Que este termo seja ainda utilizado por filósofos não é de todo estranho, embora equivocado. 
é pela razão. Sem desmerecer os esforços e até mesmo a coerência interna de ambas concepções, no contexto amplo do sistema filosófico daqueles autores, pode-se considerar uma terceira possibilidade que situar-se-ia entre ambas, isto é, que as conserva (em parte), mas, simultaneamente, também as supera. Para Höffe, Kant formulou um conceito antropológico mais fidedigno. É justamente na antropologia kantiana que o autor busca uma alternativa para posicionar-se quanto a esta questão.

No entender de Kant, o homem tem uma tendência à sociabilidade, mas também possui uma inclinação ao conflito. Se, por um lado, ele percebe que precisa e é capaz de cooperação, dar e receber apoio, em suma, viver em sociedade, por outro, ele mostra-se não só desconfiado e hostil ao coletivo, assim como egoísta e acredita-se autossuficiente. $\mathrm{Na}$ verdade, poder-se-ia argumentar que esta inclinação ao isolamento é fundamental para o processo de individuação do sujeito. Do mesmo modo, é bastante plausível defender que tanto o processo de individuação quanto de constituição da própria identidade só pode ser pensado na relação do sujeito no seio da sociedade (cf. HÖFFE, 2005). Ora, é justamente esta ambivalência e tensão no comportamento humano - o que Kant concebe como "sociabilidade insociável" - que Höffe recupera para a sua fundamentação ${ }^{9}$.

A tese da sociabilidade insociável permite uma compreensão do ser humano que evita tanto o otimismo de Aristóteles quanto o pessimismo de Hobbes e as dificuldades postas pelas respectivas proposições. Expresso de outro modo, trata-se de dois modelos antropológicos fundamentais: o modelo do conflito e o modelo da cooperação. Ora, o modelo da cooperação não nos oferece uma representação suficiente para fundamentar a exigência de uma ordem social baseada na coerção, nem tampouco oferece uma imagem adequada e condizente com a condição humana. Por outro lado, é justamente a partir do modelo do conflito que serão propostas as principais formulações do pensamento político moderno acerca da necessidade do Estado e do direito, no intuito de controlar o potencial ameaçador do ser humano e viabilizar a vida em sociedade. Daí é que se seguem as doutrinas contratualistas. O contrato social não é um fato histórico, nem se encontra inscrito em algum lugar.

9 Esta tese kantiana está explícita na quarta proposição do opúsculo Idéia de uma história universal com um propósito cosmopolita: "O meio de que a natureza se serve para levar a cabo o desenvolvimento de todas as suas disposições é o antagonismo das mesmas na sociedade, na medida em que este se torna ultimamente causa de uma ordem legal dessas mesmas disposições. Entendo aqui por antagonismo a sociabilidade insociável dos homens, isto é, a sua tendência para entrarem em sociedade, tendência que, no entanto, está unida a uma resistência universal que ameaça dissolver constantemente a sociedade" (KANT, 1995, p. 25). 
Ele é uma metáfora, um experimento intelectual que serve para pensar a legitimação do Estado.

Para Höffe, todavia, o ser humano não pode ser entendido exclusivamente pela perspectiva do conflito, mas, sobretudo, como um ser capaz também de cooperar (cf. HÖFFE, 1981, p. 104) e isso deve-se ao fato de ele não poder cogitar a sua autorrealização e o desenvolvimento fora da sociedade, isto é, fora do (mesmo) espaço em que os seus semelhantes se encontram ${ }^{10}$.

Desse modo, ainda que a atenção às diferenças constitua um momento necessário (concretude e particularidade), os direitos humanos começam por basear-se fundamentalmente na noção de dignidade humana e na igual liberdade de todos os seres humanos (generalidade). "Por um lado o princípio da liberdade igual obriga cada membro da comunidade jurídica a reconhecer as condições universais de coexistência da liberdade; por outro, impõe a cada coletividade o dever de garantir esse reconhecimento" (HÖFFE, 2003, p. 83).

O problema que se pode levantar quanto a este ponto, mencionado por Höffe, é o fato de que os direitos humanos, de acordo com a tradição, são uma herança da civilização ocidental, de modo particular, da cultura europeia. Aqui, tem-se um exemplo básico para o que foi afirmado anteriormente, acerca de uma noção antropológica fundante. Ora, sendo herança da civilização ocidental, tem-se uma elaboração que contempla um conjunto particular de características, necessidades e potencialidades humanas: aquelas do ser humano ocidental. Como pretender, portanto, que seja justamente esta noção de direitos humanos aquela que deve prevalecer? Expresso de outra forma, o que legitima uma noção construída em determinado ponto da história e provinda de uma cultura e uma geografia determinadas a exigir o reconhecimento e validade universal? Segundo Höffe, esta é uma das questões fundamentais do discurso

10 Nas suas palavras: "Os limites da liberdade humana não advêm primeiramente de fora, de destinos pulsionais, de necessidades concorrentes, de uma natureza resistente ou escassa em bens. Eles se fundamentam muito mais no fato de vários seres capazes de ação ou de liberdade partilharem o mesmo espaço de vida. Para uma vida em conjunto, o modelo de cooperação menciona boas razões. O modelo de conflitos completa-as com a descoberta de que se convive também onde não se coopera, mas onde se partilha o mesmo espaço de vida e se restringe reciprocamente a liberdade de ação. A justiça exige agora que as inevitáveis restrições à liberdade não sejam efetuadas ao estilo da natureza, de acordo com os respectivos potenciais de poder e ameaça. Disso poderiam resultar extremados privilégios e discriminações. Para que, ao contrário, cada pessoa seja elementarmente tratada de modo igual, cada uma desiste do alegado 'direito a tudo' e recebe em contrapartida liberdades correspondentes. O contrato político originário cifra-se, por isso, em uma transmissão recíproca de direitos e deveres que, com vistas à justiça, se dá de acordo com os mesmos princípios, quer dizer, de acordo com princípios universais." (HÖFFE, 2003, p. 77). 
intercultural do direito, pois entendido como instituição do direito, eles (os direitos humanos) são reconhecidos e até mesmo evidentes, porém, no que toca à sua base fundamental de legitimação, há muito tempo que não o são (cf. HÖFFE, 1998, p. 29). Com efeito, ele observa que: "Quando se relaciona os direitos humanos ao desenvolvimento do direito moderno de modo estreito, ou seja, à uma cultura e época determinada, põe-se em jogo, naturalmente à contre coeur, o que o conceito exige: uma validade simplesmente universal" (HÖFFE, 1998, p. 29).

O problema que emerge, aqui, é que, para definir o que são direitos humanos, precisa-se especificar antes o que é o ser humano, como já assinalado anteriormente. Ao procurar responder à pergunta "o que é o ser humano?", recorre-se a uma determinada imagem ou representação do mesmo e a ela relaciona-se a definição do que são os seus direitos. O problema é que se assume invariavelmente uma ideia de ser humano que tem sempre características peculiares e particulares, o que lhe confere uma validade limitada e particular, não universal. E, neste sentido, não se pode negar que estamos diante de um problema quando tentamos defender a tese de que a justiça está acima das particularidades culturais, das peculiaridades epocais e que, portanto, ela é universal.

É neste contexto que o autor vê a necessidade de uma relativização da influência ocidental moderna que paira sobre tal conceito, seguida da elaboração de um discurso intercultural para a legitimação dos direitos humanos. Para isso, a parcela de contribuição da antropologia é decisiva. O discurso intercultural poderia ser compreendido a partir de duas dimensões: a) como universalismo intercultural, isto é, pela garantia da igualdade de todo o ser humano perante a lei, independentemente de ser ele do ocidente ou do oriente, independentemente de sua condição e situação e; b) como universalismo supratemporal, isto é, na medida em que a validade dos direitos humanos independe do momento histórico em questão. Através destas duas dimensões, os direitos humanos passam a ser vistos de modo essencialmente diferente do modo como historicamente o foram. Eles não seriam mais portadores da herança cultural moderna e europeia, mas passariam a pertencer à humanidade como um todo.

\section{Direitos humanos e direitos fundamentais}

Uma diferenciação importante, para o autor em questão, é aquela que diz respeito a direitos humanos e direitos fundamentais. Höffe entende que direitos humanos são aqueles direitos que se originam do ser humano em sua condição de ser humano, ao passo que os direitos fundamentais são aqueles direitos elementares de cada cidadão no interior de um estado. Ele afirma, quanto aos direitos humanos, que são, antes, 
direitos que cada pessoa merece de modo inalienável, só pela condição de ser humano, e que nesse sentido não-biológico de moral jurídica são denominados direitos inatos, naturais, inalienáveis e invioláveis (HÖFFE, 2003, p. 83).

Nesta perspectiva, os direitos humanos antecedem os direitos fundamentais, o que lhes confere um caráter pré-estatal, enquanto os direitos fundamentais seriam uma consequência do surgimento do Estado. É preciso, contudo, lembrar que não se trata de uma anterioridade histórica, mas lógica (cf. MOREIRA, 2002, p. 37). Assim entendida, tal anterioridade implica a compreensão dos direitos humanos não como algo decorrente ou fundamentado a partir de ações voluntárias ou favores sociais ou políticos. Pelo contrário, "trata-se de direitos que os membros da comunidade jurídica devem uns aos outros e que, subsidiariamente, a ordem jurídica e estatal deve a todas as pessoas" (HÖFFE, 2003, p. 83). Enquanto as necessidades ou as pretensões comuns serão atendidas por meio das garantias fundamentais, pelo direito positivo, os direitos humanos serão, para elas, o pressuposto. Eles têm, dessa forma, um significado eminentemente moral.

No entanto, como poderíamos conceber um fundamento que possibilite a validade universal destes direitos? Quais são as condições de possibilidade para esta fundamentação? Höffe argumenta que aquele que quer legitimar direitos, tem que proceder à justificação dos respectivos deveres, isto é, a partir do conceito de direitos humanos já estão implicados deveres humanos correlatos (cf. HÖFFE, 1998,). Aqui, ele exemplifica por meio do exemplo do não exercício da violência que está em poder dos homens e, pelo qual, pode ser preservada a integridade do corpo e da vida. Ora, o autor afirma que

justamente porque a ameaça de conflito pertence a conditio humana é que não se pode seguir por muito tempo Aristóteles e entender as instituições sociais somente a partir do desenvolvimento natural dos impulsos sociais já dados (Idem, ibidem, p. 36).

Se a natureza, de um lado, viabiliza certas capacidades ou disposições para a sociabilidade no ser humano, ela não o faz já, por meio disso, um animal social. Tornar-se social é uma das grandes tarefas e consiste na principal realização humana. É uma missão que só pode ser obra própria do ser humano. E, aqui, é dado o primeiro passo neste sentido: a sociedade somente é possível por meio da renúncia à violência recíproca (negativamente) e do reconhecimento recíproco (positivamente). Antes que pensemos nas possibilidades de autorrealização, contudo, é preciso que cuidemos das condições mais elementares para que a vida humana 
seja simplesmente possível. É neste contexto que o autor menciona a questão dos interesses inatos. Há um interesse inato em que a vida não seja interrompida e que ela siga o seu curso. É irrecusável que a vida é e quer realizar-se. Ora, justamente por representarem pretensões, os direitos humanos não podem ser compreendidos como uma troca de favores ou de presentes que pode ser feita entre os sujeitos ou, até mesmo, entendidos como algo feito a partir da simpatia, da compaixão, do pedido. "Direitos humanos se legitimam a partir de uma reciprocidade, pars pro toto: a partir de uma troca" (HÖFFE, 1998, p. 37). É nesta reciprocidade que se entrecruzam um momento transcendental e um momento social e, por meio disso, temos o cerne da argumentação de Höffe: por conta da necessária relação de reciprocidade e das diferentes pretensões que possam ser postas em discussão, é preciso um argumento que leve em conta a equação "ética + antropologia". Aqui, no entanto, deve-se esclarecer o que ele entende por interesses transcendentais.

\section{Interesses transcendentais}

O termo "transcendental", neste caso, é assumido desde a perspectiva kantiana. O conhecimento transcendental ocupa-se, segundo Kant, não com os objetos, mas com o modo pelo qual nós os conhecemos. Com efeito, afirma Kant, na passagem B 25 da Kritik der reinen Vernunft: "Chamo transcendental a todo conhecimento que em geral se ocupa menos dos objetos, que do nosso modo de os conhecer, na medida em que este deve ser possível a priori. Um sistema de conceitos deste gênero deveria denominar-se filosofia transcendental." (KANT, 1998, v. II, p. 63). Ele refere-se, portanto, às condições de possibilidade de conhecimento dos objetos. É porque se trata de condições de possibilidade de ser humano ou condições de possibilidade relacionadas à capacidade de ação humana que será necessário uma revolução copernicana na Antropologia. Não se trata de definir o ser humano a partir do que lhe propicia autorrealização, sentido de vida ou felicidade. Em franca despedida do pensamento teleológico, Höffe concebe o vir-a-ser humano na perspectiva de um conceito normativo e exigente, que significa a procura das condições de realização plena do humano.

É porque se trata de condições de possibilidade - relacionadas ao ser humano, respectivamente à capacidade de ação - que se pode empregar a relevante expressão desde Kant e falar de elementos transcendentais da Antropologia ou de (relativos) interesses transcendentais (HÖFFE, 1998, p. 34). 
Em outras palavras, os interesses transcendentais conteriam tudo aquilo que já se quer quando se quer alguma coisa, independentemente de seu conteúdo e se é desejado ou evitado. Em ambos os casos, sempre se expressa um querer, que seria a condição de todo e qualquer querer. Transcendentais são, portanto, os interesses que os sujeitos agentes têm e que lhes proporcionam condições gerais para que eles ajam do modo como eles queiram agir.

Os interesses que Höffe menciona como transcendentais são, pois: o interesse pelo corpo e pela vida, sem os quais não há chances de a vida humana acontecer. Uma vida sem corpo pode até ser possível, mas não é desta forma de vida que o autor trata e, portanto, a vida sem corpo não pode ser vida. O corpo sem vida igualmente não é, ou deixa de ser. Ambos os interesses são a base de todos os demais, são condições de possibilidade da capacidade de ação humana e para um querer orientado na ação ${ }^{11}$.

O interesse natural de todo o ser humano, no corpo e na vida, é condição de possibilidade universal para a liberdade. Por isso mesmo, é que ele pode ser concebido como um interesse a priori, ou transcendental, conforme Höffe. $\mathrm{E}$ até "mesmo aquele que não está particularmente preso à vida", assim complementa o autor, "possui - consciente ou inconscientemente - este interesse, porque de outro modo não pode aspirar nem desejar, nem satisfazer um desejo." (Idem, ibidem, p. 391). Dito de modo abreviado, a vida é condição para a ação. Mas estes requisitos não são suficientes, uma vez que intencionalidade, capacidade de linguagem e de pensamento incluem-se nestes interesses, bem como as relações sociais, sem as quais o ser humano pode tornar-se verdadeiramente ser humano.

Os interesses transcendentais, além de pressupostos ou condições de possibilidades de realização de todo e qualquer outro tipo de interesse (refiro-me aos mais diversos tipos de interesses subjetivos), são caracterizados por uma sociabilidade que lhes é inerente: eles somente são realizáveis na e a partir da relação de reciprocidade. Aqui, porém, poder-se-ia perguntar: como o autor define o conceito de reciprocidade? O que exatamente os interesses transcendentais têm uma sociabilidade inerente? Para entendermos a sua efetivação é preciso que se retome ao

11 "Independentemente da questão sobre se devemos entender o corpo como organismo ou antes como sistema é importante isto: ele é o todo das 'forças' em parte conscientes, em parte inconscientes que mantêm em vida e em movimento um ser que age livremente, portanto o todo das sensações, pulsões e necessidades, das inclinações e repulsões, das paixões e considerações, bem como das possibilidades de movimento, no qual se desenrola o querer e através do qual se realiza, agindo no mundo." (HÖFFE, 1989, p. 390-391). 
ponto de partida de qualquer teoria política. Trata-se de recolocar, aqui, o que viabiliza ou, até mesmo, exige a relação entre os seres humanos. O ponto de partida é a liberdade.

Como o ser humano não surge do acaso, mas sempre dentro de um contexto e de um determinado grupo, ele é um ser essencialmente relacional e que coexiste com outros seres semelhantes. Ora, é justamente por não existir isolado ou, pelo fato de co-existir, co-habitar, con-viver que a sua liberdade não é ilimitada. De alguma maneira, a liberdade ilimitada de todos poria fim à própria liberdade de todos. "Seres livres que habitam o mesmo mundo limitam-se inevitavelmente em sua liberdade, fato no qual as limitações têm caráter coercitivo, oriundo de fora do sujeito individual" (Idem, ibidem, p 382). Ao que Höffe denomina de estado primário de natureza, corresponde à imagem sugerida por Hobbes, de uma guerra latente de todos contra todo ${ }^{12}$.

Tal liberdade de ação consiste precisamente na reivindicação do pretenso "direito a tudo", conforme exposto anteriormente. É justamente neste fato que reside a principal ameaça ao ser humano e que é manifesta através do próprio ser humano. Ele é tanto vulnerável, ameaçado, quanto ofensivo e ameaçador. Condição para evitar que a liberdade total ou ilimitada suprima a própria liberdade será, desse modo, a negação desta em benefício da coexistência de liberdades limitadas ou parciais. Faz-se necessária, pois, a renúncia recíproca deste estado primário de natureza, isto é, todos devem renunciar a ele para que a existência, a integridade e a autorrealização sejam prerrogativa de todos. Não se trata, portanto, de uma regulação espontânea, mas de uma regulação racional ${ }^{13}$.

A renúncia recíproca das liberdades é condição necessária para evitar a autoaniquilação do ser humano pelo próprio ser humano. Entretanto, ela não é, por si só, condição suficiente para garantir uma sociedade justa. Em outras palavras, a partir desta cooperação negativa não são ainda propiciados os elementos para uma cooperação positiva. É por isso que Höffe defende que a forma primária da legitimação política da justiça é a justiça comutativa e não a justiça distributiva (cf. HÖFFE, 2001, p. 344).

12 "No estado primário de natureza cada qual se reserva sua total liberdade de ação, por exemplo, a liberdade de matar seu semelhante, roubá-lo dos frutos de seu trabalho, ferir sua honra e reduzir sua liberdade de religião. Com a que se esconde na liberdade de todos, cada qual está 'automaticamente' exposto à liberdade de ação de seus semelhantes, portanto, à sua liberdade de matar, de roubar, de ofender." (HÖFFE, 2001, p. 342).

13 "Com a renúncia recíproca à liberdade, realiza-se, no estado secundário de natureza, uma troca, mais exatamente: uma troca negativa, que o recíproco dar e receber não consiste em desempenho positivo, mas em renúncias. [...] A limitação de liberdade é, portanto, permutada por uma garantia de liberdade, a renúncia à liberdade é compensada com uma pretensão de liberdade.[...] A renúncia é a condição de possibilidade para a integridade" (HÖFFE, 2001, p. 343). 
Assim sendo, a partir da legitimação política do Estado e da sociedade civil serão estabelecidas as condições mínimas para que a cooperação positiva seja instaurada.

\section{Considerações finais}

A partir dos aspectos anteriormente destacados da concepção de Höffe, gostaria de apontar, aqui - sem com isso pretender concluir a discussão -, para alguns problemas que ainda precisam ser enfrentados no que se refere à fundamentação filosófica dos direitos humanos. Para isso, tomo como referências algumas objeções levantadas às teses de Höffe, sobretudo por Thomas Kesselring (2001) e Jens Hinkmann (1999).

O primeiro aspecto que destaco é que o conceito de justiça como troca é bastante problemático. A troca transcendental, como foi exposto anteriormente, consiste fundamentalmente numa renúncia recíproca ao uso da suposta "liberdade de fazer tudo" e, através disso, estaria dado o primeiro passo para postular-se a cooperação. Uma questão para a qual Kesselring chama atenção, em franca oposição tanto ao comunitarismo ${ }^{14}$, quanto ao liberalismo, é o fato de que Höffe parte do pressuposto de que há uma situação de igualdade no momento da troca. Ora, este é o ponto que justamente precisa ser demonstrado e validado. Kesselring argumenta que numa troca de mercado, por exemplo, nem sempre é necessário que haja igualdade de valor para que a troca seja legítima. Para Höffe, é a regra de ouro que valeria como referência para a troca: "Em perspectiva moral os direitos humanos se baseiam na regra de ouro, e essa regra é um critério para a troca" (HÖFFE, 1998, p. 37). E, a regra de ouro, afirma Kesselring, "não serve justamente no contexto da troca" (KESSELRING, 2001, p. 31). O autor prossegue, fazendo a seguinte comparação:

Se formos num mercado onde podemos negociar o preço, então o negociamos em nosso próprio favor, não a favor do vendedor, como deveríamos, se seguíssemos a regra de ouro. O vendedor, por seu lado, segura o preço dele e evita concessões que lhe sejam desfavoráveis. Mais até: se os atores, no mercado, começassem a comprar e vender seguindo a regra de ouro, o mercado enquanto tal se destruiria ou auto-implodiria. (Idem ibid., p. 31).

14 Na perspectiva de Kesselring, tanto o liberalismo quanto o comunitarismo não oferecem uma fundamentação filosófica suficiente para os direitos humanos, pois o primeiro, ao conferir a primazia ao indivíduo, não daria conta de uma proposta universal, enquanto que o segundo, ao priorizar um coletivo de indivíduos ou um determinado grupo, também não atenderia a demanda da universalidade. Embora o autor limite-se a afirmar, no final de seu texto, que a sua proposta é situada a meio caminho entre o liberalismo e comunitarismo, ele não expõe os desdobramentos da mesma. 
É preciso, no entanto, assinalar que a troca de que Höffe trata não é de natureza mercantil. De certo modo, Kesselring quer chamar atenção para a inadequação do conceito de troca para o contexto da fundamentação dos direitos humanos.

Outro problema para o qual a tese da troca transcendental remete é o de que a cooperação negativa (renúncia recíproca parcial das liberdades) precisa ser ainda melhor explicitada. A legitimidade da troca consiste exatamente no fato de ser voluntária. Pode-se, por exemplo, trocar certa quantidade de dinheiro por uma viagem ou por um determinado bem, mas não temos qualquer obrigação de fazê-lo. Na visão de Kesselring a troca efetuada no Estado Natural, que possibilitaria os direitos humanos, tem que ser legítima e, para isso, voluntária. Logo, ele questiona: "como podemos explicar o motivo dessa troca? Será que ela é de fato voluntária?" (Idem, ibid., p. 31). Com esse questionamento, ele quer sugerir que numa situação desigual no Estado Natural, isto é, na condição de que alguns são mais fortes e outros mais fracos, ficaria difícil crer que os mais poderosos teriam interesse em renunciar parcialmente à sua condição de poder e liberdade. O que os levaria a tal? Como podemos acreditar que esta troca é harmoniosa e faz-se livre de conflitos? Além disso, não está claro que "liberdades" teriam que ser renunciadas para estabelecer a troca em sentido negativo.

Entre as objeções que Hinkmann postula, eu destaco a questão de que o conceito de interesse como ponto de partida para a fundamentação filosófica dos direitos humanos deve pressupor além de uma antropologia transcendental, aspectos mínimos de um antropologia empírica. Os humanos são seres que são, no mínimo, capazes de sensibilidade (empfindungsfähiges Wesen), isto é, seres que contam com a faculdade de desejar, sentir prazer ou dor. Conforme Hinkmann "uma entidade que não tem esta capacidade de sensibilidade, que não consegue desejar, sentir dor ou prazer também não terá capacidade de ter interesses" (HINKMANN, 1999, p. 94). Ora, se assim é correto afirmar, então precisamos incluir entre os seres que têm aquela qualidade, isto é, seres capazes de sensibilidade, não apenas os humanos, mas também os animais e outros seres vivos e isso tornaria o conceito de direitos humanos diluído ou diluível, na medida em que, por este caminho, os interesses teriam que ser considerados não apenas em relação aos humanos e, consequentemente, trataríamos não mais de direitos somente humanos. Cabe perguntar, neste sentido, se somente seres dotados da capacidade de pensar, falar e cooperar estariam incluídos no processo?

O segundo aspecto das considerações de Hinkmann diz respeito à ideia de cooperação. A simples renúncia recíproca à liberdade total não proporciona, por si só, a troca de interesses, pois uma troca é 
essencialmente positiva, isto é, deve ser entendida como uma troca de bens, visto que a liberdade não pode ser definida apenas pela negação de um estado natural. Neste sentido, a argumentação de Höffe é, na opinião do autor, insuficiente e a compreensão da liberdade em sentido positivo fica comprometida.

Além destas considerações, pode-se indagar se e em que medida é legítimo postular uma troca de interesses como base de fundamentação de uma ética: que garantias podem assegurar que não se trata do seguimento de conselhos de prudência ou mandamentos (regras) da habilidade/inteligência? Neste caso, tratar-se-ia de uma estrategização da ética?

Gostaria de finalizar este trabalho, sinalizando para o fato de que a fundamentação filosófica dos direitos humanos ainda está em processo. As controvérsias, neste campo, ainda persistem e acompanham o debate sobre ética e filosofia política. É, portanto, um assunto ainda inconcluso, que permite muitas possibilidades de interpretação e caminhos diversos quanto à fundamentação. A proposta de Höffe, neste aspecto, tem os seus méritos enquanto serve de referência para se pensar um caminho possível de fundamentação, mas como toda proposta é passível de correção e complementação.

\section{Referências}

ANDERS, Günther. Die Antiquiertheit des Menschen II. Über die Zerstörung des Lebens im Zeitalter des dritten industrellen Revolution. 3. Aufl. Munique: C.H. Beck, 2002.

GOSEPATH, Stefan; LOHMANN, Georg (orgs.). Philosophie der Menschenrechte. Frankfurt am Main: Suhrkamp, 1998.

GÖLLER, Thomas (org.). Philosophie der Menschenrechte. Methodologie, Geschichte, Kultureller Kontext. Göttingen: Cuvillier Verlag, 1999.

HINKMANN, Jens. Der Tausch von Interessen - ein universalistischer Begründungsversuch. In: GÖLLER, Thomas (org.). Philosophie der Menschenrechte. Methodologie, Geschichte, Kultureller Kontext. Göttingen: Cuvillier Verlag, 1999, p. 88-100.

HÖFFE, Otfried. A democracia no mundo de hoje. Trad. Tito Lívio Cruz Romão. São Paulo: Martins Fontes, 2005.

. Justiça Política. Fundamentação de uma filosofia crítica do direito e do Estado. Trad. Ernildo Stein. São Paulo: Martins Fontes, 2001.

. O que é Justiça? Trad. Peter Naumann. Porto Alegre: Edipucrs, 2003.

. Politische Gerechtigkeit. Grundlegung einer kritischen Philosophie von Recht und Staat. Edição revista e ampliada. Frankfurt am Main: Suhrkamp, 1989.

. Sittlich-politische Diskurse. Philosophische Grundlagen Politische Ethik, Biomedizinische Ethik. Frankfurt am Main: Suhrkamp, 1981. 
HÖFFE, Otfried. Transzendentaler Tausch. Eine Legitimationsfigur für Menschenrechte? In: GOSEPATH, Stefan; LOHMANN, Georg. Philosophie der Menschenrechte. Frankfurt am Main: Suhrkamp, 1998.

. Wirtschaftsbürger, Staatsbürger, Weltbürger. Politische Ethik im Zeitalter der Globalisierung. Munique: C.H. Beck, 2004.

KANT, Immanuel. Werke in sechs Bänden. Hrsg. von Wilhelm Weischedel. Darmstadt, 1998.

. Idéia de uma história universal com um propósito cosmopolita. In: KANT, Immanuel. A paz perpétua e outros opúsculos. Trad. de Artur Morão. Lisboa: Edições 70, 1995.

KESSELRING, Thomas. A troca transcendental - análise de um conceito central na teoria de Otfried Höffe. In: Veritas, Porto Alegre: PUCRS, 46 (1) (2001), p. 29-33.

KERSTING, Wolfgang (org.). Gerechtigkeit als Tausch? Auseinandersetzungen mit der politischen Philosophie Otfried Höffes. . Universalismo e Direitos Humanos. Porto Alegre: Edipucrs, 2003.

MOREIRA, Luiz. Direitos Humanos: a proposta transcendental de Otfried Höffe. In: Síntese - Revista de Filosofia, Belo Horizonte, 29 (93) (2002), p. 35-47.

RUFFIÉ, Jacques. De la Biología a la Cultura. Trad. Elena Rotés. Barcelona: Muchnik Editores, 1982. 